\title{
BMJ Global Health Innovative financing to fund surgical systems and expand surgical care in low-income and middle-income countries
}

\author{
Ché L Reddy (1) , ${ }^{1,2}$ Alexander W Peters, ${ }^{1,3}$ Desmond Tanko Jumbam (1) ,,2 \\ Luke Caddell, ${ }^{1}$ Blake C Alkire, ${ }^{1,4,5}$ John G Meara, ${ }^{1,2}$ Rifat Atun (i) ${ }^{6,7}$
}

\begin{abstract}
To cite: Reddy CL, Peters AW, Jumbam DT, et al. Innovative financing to fund surgical systems and expand surgical care in low-income and middleincome

countries. BMJ Global Health 2020;5:e002375. doi:10.1136/ bmjgh-2020-002375
\end{abstract}

Handling editor Seye Abimbola

Received 9 February 2020

Revised 6 April 2020

Accepted 7 April 2020
Check for updates

(C) Author(s) (or their employer(s)) 2020. Re-use permitted under CC BY-NC. No commercial re-use. See rights and permissions. Published by BMJ.

For numbered affiliations see end of article.

Correspondence to Dr Ché L Reddy; chelen_reddy@hms.harvard. edu

\section{ABSTRACT}

Strong surgical systems are necessary to prevent premature death and avoidable disability from surgical conditions. The epidemiological transition, which has led to a rising burden of non-communicable diseases and injuries worldwide, will increase the demand for surgical assessment and care as a definitive healthcare intervention. Yet, 5 billion people lack access to timely, affordable and safe surgical and anaesthesia care, with the unmet demand affecting predominantly low-income and middle-income countries (LMICs). Rapid surgical care scale-up is required in LMICs to strengthen health system capabilities, but adequate financing for this expansion is lacking. This article explores the critical role of innovative financing in scaling up surgical care in LMICs. We locate surgical system financing by using a modified fiscal space analysis. Through an analysis of published studies and case studies on recent trends in the financing of global health systems, we provide a conceptual framework that could assist policy-makers in health systems to develop innovative financing strategies to mobilise additional investments for scale-up of surgical care in LMICs. This is the first time such an analysis has been applied to the funding of surgical care. Innovative financing in global surgery is an untapped potential funding source for expanding fiscal space for health systems and financing scale-up of surgical care in LMICs.

\section{INTRODUCTION}

In 2019, at the 74th United Nations (UN) General Assembly, the UN Member States recommitted to achieving Universal Health Coverage (UHC) for a healthier world by $2030 .{ }^{1}$ In 2015 , the 68th World Health Assembly committed to strengthen surgery and anaesthesia care as a component of UHC. ${ }^{2}$ However, many low-income and middle-income countries (LMICs) are unable to provide universal access to safe, timely and affordable surgical care, including obstetric $^{3}{ }^{4}$ and anaesthesia ${ }^{3}$ for several reasons, including: low-quality surgical

\section{Summary box}

- Inadequate funding of national surgical care programs restrains the expansion of quality surgical care in LMICs.

- Innovative financing has helped to fund numerous global health priorities at scale but is yet to be harnessed to fund surgical systems.

- The development of innovative financing instruments and mechanisms is an untapped funding source to expand the fiscal space for surgical care scale-up. It is also an opportunity to develop novel financing instruments based on the contextual specificities of a country, and region.

- We analyse published studies and recent trends in health system financing, together with successful innovative financing case studies to provide a conceptual and interpretive framework. The framework could enable policymakers (and other relevant actors) to design, introduce and scale-up innovative financing mechanisms for surgical care in LMICs.

services, ${ }^{356}$ insufficient surgical workforce, ${ }^{7-9}$ poor infrastructure ${ }^{10-12}$ and, importantly, weak governance and suboptimal organisation of health systems. ${ }^{1314}$

In addition to weak governance and suboptimal organisation of health systems, ${ }^{13}{ }^{14}$ for LMICs, a major constraint to the provision of quality surgical care is inadequate financing. ${ }^{15}$ In the context of diminishing Development Assistance for Health (DAH),${ }^{16-18}$ constrained national budgets and competing health priorities, new strategies are needed to expand fiscal space for health to finance scale-up of surgical services. Fiscal space refers to the ability of a government to increase overall public spending without compromising macroeconomic stability. ${ }^{19}$ Innovative financing, which has been taken to scale in global health to finance AIDS, tuberculosis, malaria and vaccine-preventable diseases in 
LMICs, ${ }^{19-21}$ provides an opportunity for new and additional funding for scale-up of surgical care in LMICs.

Many LMICs have sought to strengthen their health systems by developing strategic plans-National Surgical, Obstetric and Anaesthesia Plans (NSOAPs)-explicitly designed to improve surgical care. ${ }^{22-25}$ Despite the specific intention of NSOAPs to help improve health system performance in $\mathrm{LMICs}^{26}$ and attain the UN Sustainable Development Goals, ${ }^{27}$ the potential impact of NSOAPs have been constrained by limited financing to support their implementation. To provide sustainable funding for NSOAPs and to effectively scale-up surgical care, a more systematic and comprehensive approach to financing is required.

This article explores the role of innovative financing in scaling up surgical care. We locate surgical system financing within a modified fiscal space analysis to explore strategies to increase funding for health systems. Based on an examination of the trends in health system financing and an evaluation of the cost of NSOAPs, we provide a conceptual framework that could be useful for policymakers in LMICs to mobilise additional financial investment for surgical systems.

\section{FINANCING THE EXPANSION OF SURGICAL CARE IN LMICS}

\section{National surgical, obstetric and anaesthesia plans}

NSOAPs are strategic plans embedded within country National Health Plans that aim to improve surgical care. In 2015, the Lancet Commission on Global Surgery, recommended an NSOAP framework (figure 1) that countries could use to improve surgical care. ${ }^{26}$ NSOAPs are an example of a complex health policy innovation that involves multiple stakeholders and interrelated elements of a health system. ${ }^{28}$ NSOAP implementation produces many changes at all levels and within all functionaldomains of the health system; involves multiple stakeholders with diverse interests working together towards a common goal of improving surgical care, and disrupts the established institutional logic ${ }^{29}$ within surgical provider groups and promotes new ways of functioning. Complex innovations require consistent leadership and a well-coordinated process for implementation, in which financing reform is approached in an integrated fashion, alongside other functional modifications in a health system. $^{30}$ The NSOAP framework addresses this challenge by utilising a 'systems' approach to the implementation process: changes in financing are considered in terms of other elements of a health system-for example, service delivery, workforce, infrastructure, information management, finance and governance-to provide a unified and integrated approach to improving surgical care in a country.

Since 2015, several countries have developed and begun implementing NSOAPs as a means to improve surgical care and to simultaneously strengthen health systems. ${ }^{12}$ 31-35 In addition to country-level activities, there are regional initiatives to improve surgical care worldwide. ${ }^{36}$

Without a financing strategy, however, the development and implementation of NSOAPs will be restrained. Experience to date suggests that the cost of implementing NSOAPs range from US $\$ 69.7$ million in Rwanda ${ }^{32}$ to US $\$ 16.8$ billion in Nigeria. ${ }^{34}$ The Tanzanian NSOAP is estimated to cost an additional US $\$ 1.51$ per capita per

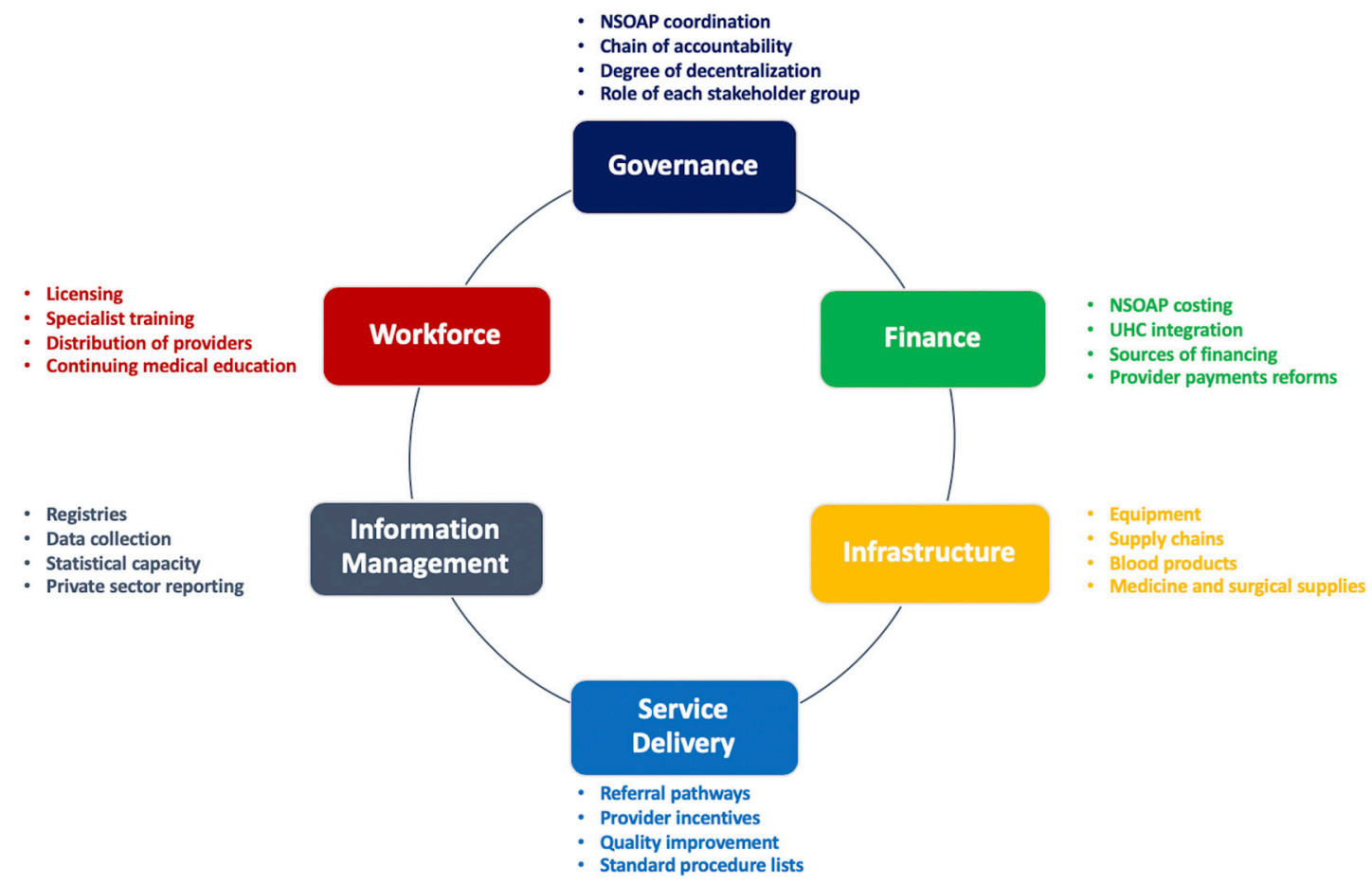

Figure 1 The six domains of National Surgical, Obstetric and Anaesthesia Plans (NSOAPs) Source: Adapted from Citron et al. ${ }^{59} \mathrm{UHC}$, Universal Health Coverage. 


\begin{tabular}{|c|c|c|c|c|c|c|c|}
\hline Country & $\begin{array}{l}\text { GDP per capita } \\
\text { (World Bank } \\
2017 \text { ) }\end{array}$ & $\begin{array}{l}\text { Population } \\
\text { (World Bank, } \\
\text { 2018) }\end{array}$ & $\begin{array}{l}\text { NSOAP } \\
\text { years }\end{array}$ & $\begin{array}{l}\text { Total NSOAP } \\
\text { cost }\end{array}$ & $\begin{array}{l}\text { NSOAP cost } \\
\text { per year per } \\
\text { capita }\end{array}$ & $\begin{array}{l}\text { NSOAP cost/cap } \\
\text { as a percentage of } \\
\text { GDP/cap }\end{array}$ & $\begin{array}{l}\text { NSOAP cost/cap as a } \\
\text { percentage of health } \\
\text { spending/cap }\end{array}$ \\
\hline Zambia & US\$1509.80 & 17.3 million & 5 years & US\$314 million & US\$3.62 & 0.24 & 6.49 \\
\hline Tanzania & US\$936.33 & 56.3 million & 7 years & US\$597 million & US\$1.51 & 0.16 & 4.20 \\
\hline Rwanda & US\$748.39 & 12.3 million & 6 years & US\$69.7 million & US\$0.94 & 0.13 & 1.98 \\
\hline Nigeria & US\$1968.56 & 195.9 million & 5 years & US $\$ 6.8$ billion & US\$17.12 & 0.87 & 22.18 \\
\hline
\end{tabular}

Source: Jumbam et al. ${ }^{15}$

GDP, gross domestic product; NSOAP, National Surgical, Obstetric and Anaesthesia Plans.

year annualised over a 7-year implementation phase, on top of the US $\$ 35.5$ per capita annual spending on health. ${ }^{153337}$

Though NSOAPs are fully costed (table 1), there are few, if any, financial commitments from domestic, external or private sources for their implementation. If a country cannot finance an NSOAP, it is unlikely to implement it—a major obstacle to scaling up surgical care globally.

\section{Financing surgical systems}

Financial investment in surgical care is very low at global and national levels. ${ }^{26}{ }^{38}$ In LMICs, the sources of health system financing include government spending, private insurance and out-of-pocket expenditure at the national level, and DAH from international sources.

Globally, in 2018, the majority of the US $\$ 38.9$ billion in DAH was allocated to infectious diseases (US $\$ 15.1$ billion; $39 \%$ ), child health and maternal health (US\$12.4 billion; $32 \%$ ) and health system strengthening (US\$5.4billion; $14 \%$ ). Non-communicable diseases (chronic diseases, injuries and cancers), under which many surgical-related conditions are categorised, accounted for US $\$ 0.78$ billion, approximately $2 \%$ of DAH (figure 2). Since 2010, DAH has not increased substantially: the annual DAH growth rate of $4.6 \%$ in the $1990 \mathrm{~s}$ fell to $1.8 \%$ between 2010 and $2016 .{ }^{16}$ This decline is likely related to the global economic recession that began in 2008, which primarily affected donor countries and led them to encourage recipient countries to increase domestic spending and reduce dependence on external financing. ${ }^{39}$ Given the current uncertainty in both the global economic and political outlook, further growth in DAH is unlikely to increase substantially in the near future.

Many LMICs lack domestic resources to increase healthcare spending, where governments need to address multiple, competing development priorities simultaneously in uncertain political and economic contexts. As a result, many LMICs are unable to expand domestic health spending sufficiently and are dependent on DAH. In 2016, among countries in sub-Saharan Africa alone, external sources constituted more than one-third of the total health expenditure (THE) in 15 countries (figure 3) ${ }^{40}$ In South Africa, the second-largest economy in Africa, THE constituted $8.11 \%^{37}$ of gross domestic product, one of the highest in the African continent and $13.5 \%^{41}$ of the total government expenditure, but below the recommended target of $15 \%$ of government budget established by the African Union Members States in the Abuja Declaration. ${ }^{42}$ In Nigeria, Africa's largest economic nation, the health budget approximated $3.57 \%$ of the national fiscus in 2019, well below the target established by the Abuja Declaration. ${ }^{43}$

Given the decline in DAH and inadequate government contributions to health from traditional budget sources, national governments will need alternative sources of financing and imaginative strategies to increase domestic funding for health. Indeed, it may be challenging to scale-up essential healthcare interventions (eg, comprehensive HIV care), given the constrained fiscal environments that characterise LMICs, without mobilising

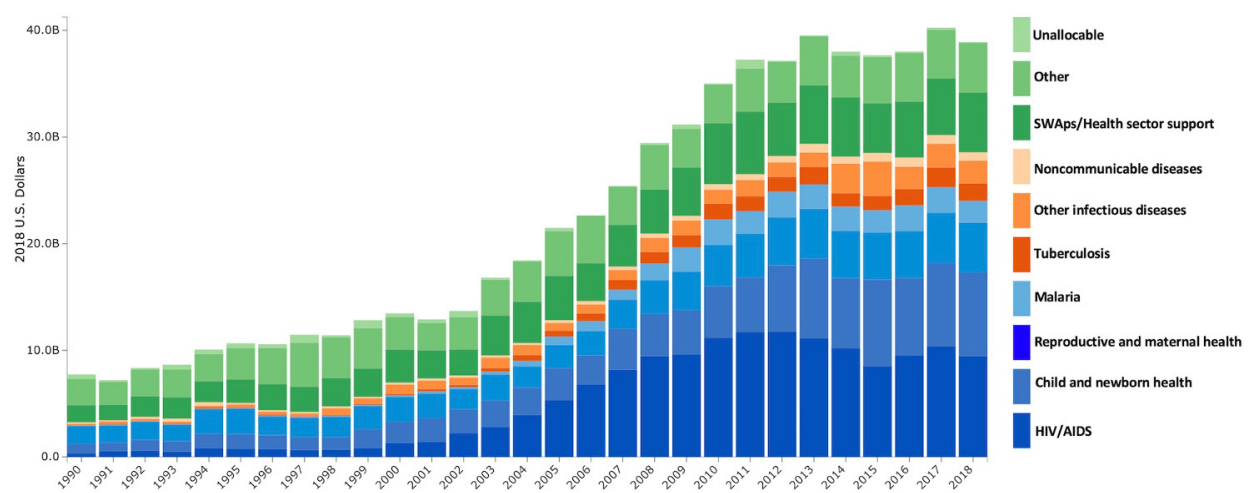

Figure 2 Health focus areas for DAH: 1990-2018 Source: Financing Global Health (No changes). ${ }^{60}$ DAH, Development Assistance for Health. 


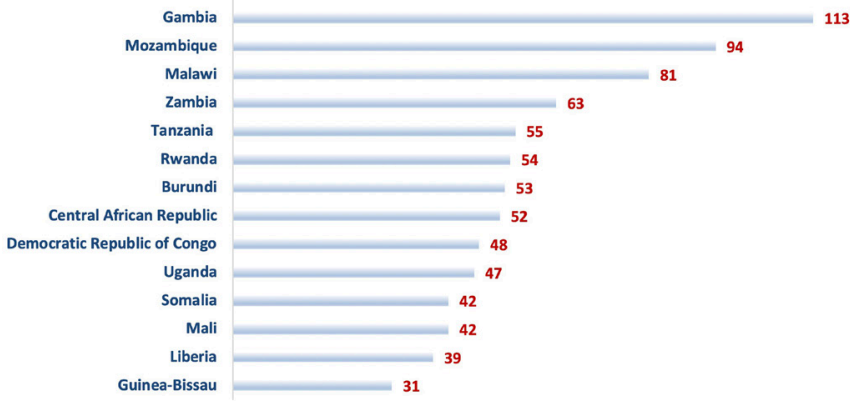

Figure 3 DAH percentage of total health expenditure for southern African countries. Source: financing global health. ${ }^{60}$ DAH, Development Assistance for Health.

investment using innovative strategies. ${ }^{44}$ So: how can governments in LMICs increase funding for healthcare through new funding strategies?

\section{INNOVATIVE FINANCING MECHANISMS \\ Innovative financing}

Though varied definitions of innovative financing exist, ${ }^{45-48}$ it can best be described by contrasting it with traditional forms of health financing. The latter refers to a combination of three streams of funding for health systems: state (public), private (user out of pocket fees and private health insurance), and external entities (DAH). With traditional financing, monetary commitments are typically linked to health system inputs (eg, human resources, infrastructure, medicines) or outputs such as health services. By contrast, innovative financing comes from new sources that are different from traditional finance and is intrinsically linked with creating higher value in health system performance (improved population health, financial protection and patient satisfaction, with higher efficiency). Innovative financing involves novel sources of funding and new strategies for pooling funds, as well as the use of market mechanisms and incentives to improve the performance of funded programmes. ${ }^{47}$ It is thus the manner in which funds are mobilised, pooled and allocated to produce greater value in health system performance that distinguishes innovative financing over the traditional form. ${ }^{47}$

The value chain approach provides a useful framework to describe innovative financing (figure 4). By tracking the transformation of funds-mobilisation, pooling, channelling, allocation and implementation-it is possible to explore how innovation occurs at various steps of the value chain to improve the production of particular health services and enhance overall system performance (see box 1). Innovation in this context is conceived as any new idea, thing, practice or institutional arrangement that is perceived as novel to the system. ${ }^{49}$

\section{Innovative financing for global health}

Several innovative financing instruments (IFIs) have been effectively deployed and scaled-up for funding global health activities (box 2, table 2) $\cdot{ }^{19}$ Some of these instruments could be adapted and used to finance surgical systems. IFI's 'innovate' in terms of how funds are mobilised, while innovative financing mechanisms,

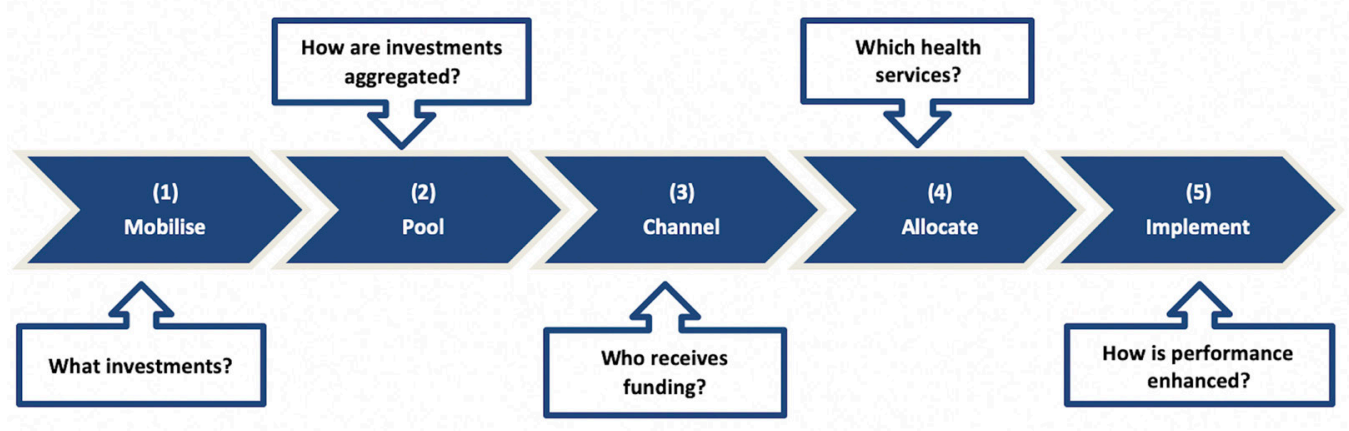

1) Mobilise: What funding sources are being used for the innovative mechanism? Mobilisation refers only to the process of obtaining funding and stops when funding enters the pooling mechanism. Sources may be obtained from traditional sources or innovative financing instruments.

2) Pool: How are the funding sources combined? The pooling process begins when funding is received and ends when funds are disbursed. Pooling can occur at a global, regional, national or even sub-national levels.

3) Channel: Which implementing entities receive funding? Entities are variable and may include governments, or civil society organizations, private sector, or combinations of institutions. The channeling process begins when funding leaves the pooling mechanism and ends when funds reach an implementing entity.

4) Allocate: What healthcare services receive funding? Allocation can occur to single interventions (vaccinations), combinations (surgical conditions) or systems strengthening activities (supply chains, or governance). Allocation begins and ends when an implementing entity uses channeled funds to pay for specific health activities.

Implement: How is implementation performance increased? This may include a variety of strategies from performance-based funding to incentives that foster enhanced collaboration or organizational management. This process begins once an implementing entity receives pooled funds and ends at project completion term.

Figure 4 Value chain framework for innovative financing Source: Adapted from Atun et al. ${ }^{47}$ 
Box 1 Financing value chain in an innovative financing mechanism

We can illustrate the functioning of the value chain in an innovative financing mechanism that has reached a global scale: The Global Fund to Fight AIDS, Tuberculosis, and Malaria (Global Fund). The Global Fund mobilises funds from several sources: bilateral funding mainly from donor governments, but also from private foundations such as the Bill \& Melinda Gates Foundation, private corporations and philanthropic organisations. ${ }^{47}$ Importantly, it can expand resource mobilisation from non-traditional sources using innovative financing instruments, such as Product (RED) and debt swaps, which are discussed below. ${ }^{19}$ For the year 2018, the Global Fund was able to mobilise US\$6.8 billion of funding to allocate to the programmes it supports. ${ }^{61}$ These resources are pooled and channelled through a dual-track financing approach that entails disbursing funds to both governments and local nongovernmental organisations for programme implementation. Emphasis is placed on accountable governance; decisions to channel funds are determined by an interdisciplinary review panel that involves a broad range of stakeholders, including patient advocacy groups-a group excluded from health planning and decision-making processes. Funds are allocated to HIV/AIDS, tuberculosis and malaria programmes, and for health system strengthening. ${ }^{62}$ Finally, implementation is supported through performance-based funding with incentives that encourage the achievement of programmatic goals with a transparent reporting process.

which integrate all elements of the financing value chain, pool, channel, allocate funds and improve the performance of implementing entities to achieve more significant impact through the use of incentives. Innovative mechanisms expand the pool of funding through a combination of IFI's and traditional sources of financing. Thus, while IFI's help to mobilise funds that might be otherwise unavailable for health spending, Innovative Financing Mechanisms transform these funds in novel ways to generate higher value for health systems.

We discuss IFI's that have mobilised funding in different manners to expand fiscal space for health systems in LMICs, for infectious diseases (HIV/AIDS, tuberculosis and malaria), maternal and child health (vaccinations) and environmental health (climate change) ${ }^{50}$ These IFI's can be grouped into four broad categories (table 3) that include voluntary solidarity levies (Unitaid/Airline Levy), voluntary contributions (PRODUCT(RED)), performance-based instruments (Advanced Market Commitments), and bonds and other securities (GAVI bonds, Children's Investment Fund Foundation (CIFF) $).^{50}$

\section{INNOVATIVE FINANCING FOR SURGICAL SYSTEMS Situating innovative mechanisms within health system financing processes}

How can governments and global entities use IFIs and mechanisms to increase funding for scale-up of surgical programmes in LMICs? A framework is needed to unify innovative financing practices within the broader health
Box 2 Innovative financing instruments

\section{Voluntary Solidarity Levy: Unitaid}

In 2006, Unitaid was established to create favourable market dynamics for expanded access to medicines at scale to combat the three pandemics affecting low-income and middle-income countries (LMICs), namely HIV/AIDS, tuberculosis and malaria. While some of Unitaid's funding comes from donor governments as Development Assistance for Health and from large foundations, the majority of its revenue is sourced from a small levy placed on airline tickets sold in several countries. This levy, which is small enough per ticket to be undiscernible to airline customers, has served to create a sustainable revenue stream for Unitaid's operations through the participation of LMICs and high-income countries. The revenues from the airline levy have been more predictable and consistent than the funding streams based on government grants and fundraising cycles and have enabled Unitaid to mobilise more than one billion Euros between 2006 and 2013.

\section{Voluntary contribution: PRODUCT (RED)}

In 2006, Bono and Bobby Shriver launched '(RED)' to raise money for the Global Fund to tackle HIV/AIDS in eight African countries. ${ }^{63}$ (RED), also known as PRODUCT(RED)', seeks to raise money from the private sector and raise public awareness of HIV/AIDS by partnering with large global brands, including Apple, Air Asia, Bank of America, Amazon, Durex, Nike and Starbucks to create (RED) branded products. Every purchase of a (RED) branded product activates a corporate contribution to the Global Fund. (RED) seeks to use private sector partnerships to raise money for the Global Fund and to increase awareness of the Global Fund's efforts to reduce the HIV/AIDS burden in Africa. ${ }^{64}$ Between 2006 and 2018, (RED) raised more than US\$600 million of funding for the Global Fund. ${ }^{63}$

\section{Performance-based instruments: GAVI}

In 2009, the British, Canadian Italian, Norwegian and Russian governments, and the Bill \& Melinda Gates Foundation, funded an Advance Market Commitment (AMC) to reduce the impact of pneumococcal disease on children in $\mathrm{LMICS}^{65}$ The purpose of the AMC is to incentivise vaccine manufacturers to develop vaccines tailored to the specific needs of LMICs and scale-up manufacturing of these new vaccines by guaranteeing an initial purchase price and quantity of vaccines for purchase. With the pre-established commitment for volumes and predictable pricing, the pneumococcal AMC was able to attract manufacturers to develop vaccines that might not otherwise be available. AMC has enabled the development of new pneumococcal vaccines that were funded by GAVI to enable eligible LMICs to immunise 149 million children by 2017 , resulting in the prevention of 655000 deaths by $2020 .^{65}$

\section{Bonds and Securities: International Finance Facility for Immunisation, and The Children's Investment Fund Foundation (CIFF):}

GAVI, the Vaccine Alliance (formerly the Global Alliance for Vaccines and Immunisation), was created to expand access to immunizations for children in LMICs. ${ }^{66}$ In 2006, the International Finance Facility for Immunisation (IFFIm) was established to access capital markets to mobilise funding for new vaccines and to 'frontload' funding to rapidly scale-up immunisation programmes in LMICs. IFFIm leverages long-term donor commitments to issue 'Vaccine Bonds' on the public market to finance its operations. ${ }^{66}$ To pay interest on these bonds, IFFIm secures long-term (20-30year) contribution 'commitments' or 'pledges' from governments that are contributed in instalments

Continued 


\section{Box 2 Continued}

over time, as governments are subject to their own budget rules that prevent them from allocating funding beyond a few years and in many cases, such as the USA to an annual budgeting and appropriation process. These long-term commitments create a predictable funding stream that can be used to guarantee and pay off bonds that IFFIm issues in capital markets. The funding that is mobilised from bond issuance provides large amounts of upfront capital that can be used to frontload immunisation programmes to accelerate access. Through its Vaccine Bonds, IFFIm has mobilised more than US $\$ 6.0$ billion in funds for GAVI . ${ }^{1667}$

The CIFF is an independent, privately funded philanthropic organisation based in the UK whose mission is to transform the lives of poor and vulnerable children. ${ }^{68}$ CIFF functions as a private investment fund, similar to an endowment, with a diverse investment portfolio that aims to achieve a $6 \%$ annual rate of return (over a 10 -year basis) to support philanthropic activities through annual grant disbursements that total $5 \%$ of its fund. ${ }^{68}$ This arrangement has enabled CIFF to continue to grow while still making annual contributions to projects in line with CIFF's mission. CIFF has also committed to responsible investments and limits investment in companies that do not align with its mission, such as tobacco and fossil fuel companies, ${ }^{69}$ and those that do not commit to the International Code of Marketing Breast-Milk Substitutes. ${ }^{68}$ In 2017, CIFF had US $\$ 5.2$ billion endowment under management, generated $15.8 \%$ in net investment returns, and disbursed US\$208.3 million in grant funding to programmes focused on childhood and adolescence (US\$139 million), climate change (US\$65 million) and child protection (US\$6 million). ${ }^{70}$

system financing processes. An approach using fiscal space analysis provides the basis for such a framework.

First defined by Heller, fiscal space refers to the ability of a government to increase overall public spending without compromising macroeconomic stability. ${ }^{51} \mathrm{In}$ 2010, Tandon and Cashin adapted the fiscal space analysis approach to the health sector. ${ }^{52}$ We modified the fiscal space approach to include innovative financing (table 3). The purpose of using fiscal space analysis is to provide a systematic means for policy-makers to evaluate potential funding sources for the health sector in general and to identify new sources of funding for implementation of an NSOAP.

Fiscal space analysis has been used in several countries to both determine new funding sources, and evaluate existing strategies to increase health sector spending, ${ }^{5354}$ but no country has yet considered in this analysis innovative financing as a potential source of funding. A modified fiscal space analysis should include innovative financing together with the five 'typical' sources or drivers, of resource mobilisation in a country: (1) macroeconomic conditions; (2) government budget allocated to the health sector; (3) allocation of health sectorspecific resources; (4) improved health system efficiency and (5) funding from external sources.

General tax revenues or health promoting taxes (eg, tobacco and alcohol tax) or removal of ineffective global energy subsidies would be useful new sources 
Table 3 Components of fiscal space

\begin{tabular}{|c|c|}
\hline Fiscal space pillar & Explanation and example \\
\hline 1. Macroeconomic conditions & $\begin{array}{l}\text { Increased GDP growth } \\
\text { For example, sustained economic growth in Turkey, from } 2000 \text { to } 2008 \text {, allowed the } \\
\text { government to increase public sector funding for health at an average annual growth rate of } \\
9.1 \% \text {, paving the way for UHC scale-up. }{ }^{71}\end{array}$ \\
\hline $\begin{array}{l}\text { 2. Reprioritisation of } \\
\text { government budget }\end{array}$ & $\begin{array}{l}\text { Increased health budget as a proportion of national fiscus } \\
\text { For example, Increasing country health budgets to } 15 \% \text { of the national GDP in African nations, } \\
\text { as outlined by the Abuja Declaration. }{ }^{42}\end{array}$ \\
\hline $\begin{array}{l}\text { 3. Health sector-specific } \\
\text { resources }\end{array}$ & $\begin{array}{l}\text { Sugar-tax to finance diabetic screening at primary healthcare level } \\
\text { For example, Introducing excise taxes on specific goods or purchases such as tobacco, }{ }^{72} \\
\text { alcohol }^{73} \text { or sugar and reducing emergency subsidies. }{ }^{74}\end{array}$ \\
\hline $\begin{array}{l}\text { 4. Efficiency of existing } \\
\text { resources }\end{array}$ & $\begin{array}{l}\text { Evaluation of National Health Accounts to identify and reduce wasteful expenditure } \\
\text { Improving both technical and allocative efficiency could provide an efficiency gain of up to } \\
\text { US\$8 per capita. }{ }^{75}\end{array}$ \\
\hline 5. External sources & $\begin{array}{l}\text { Increase funding from bilateral organisations } \\
\text { For example, the United States Agency for International Development (USAID) channelled } \\
\text { US } \$ 27.2 \text { million to The Human Resources for Health programme in Rwanda, which allowed the } \\
\text { country to rapidly increase physicians needed to delivery Universal Health Coverage. }{ }^{76}\end{array}$ \\
\hline 6. Innovative financing & $\begin{array}{l}\text { Global Fund financing of antiretrovirals to support a National HIV/AIDS programme } \\
\text { For example, US } \$ 973395559 \text { disbursed to South Africa helped to provide anti-retroviral's to } \\
4.35 \text { million people with HIV/AIDS }\end{array}$ \\
\hline
\end{tabular}

Source: Adapted from Tandon and Cashin ${ }^{52}$.

GDP, gross domestic product; UHC, Universal Health Coverage.

of financing, and have been used in LMICs and could provide additional revenues for the government. ${ }^{55} 56$ Innovative financing would complement such taxes to generate new and additional sources of funds. An assessment and optimisation of all funding sources, together with a plan to generate additional funds from innovative financing, could provide countries with a comprehensive strategy to explore potential sources of funding to finance NSOAPs.

\section{Developing an innovative financing strategy}

The proposed framework (figure 5) consists of three components: the 'drivers of health system spending' or fiscal space, the innovative financing strategy, and the surgical system. The surgical system exists within the broader health system-a dynamically complex environment ${ }^{49}$ that consists of multiple actors, a constantly evolving context and non-linear cause-effect relationships. ${ }^{49}$ The innovative financing strategy is influenced in both directions-by the health system and the fiscal space-which, in turn, shape the innovative financing value chain. Each component of the value chain interacts with others. The five drivers of fiscal space are co-dependent and relational. The health budget cannot increase without macroeconomic growth. Macroeconomic growth will not occur without the efficient allocation of resources by a government. Further, the degree to which innovative financing attains surgical system goals, will in turn, influence subsequent fiscal space analyses, the feasibility of mobilising additional investment and future innovative financing strategies. Thus, the nature of the interaction between value chain elements in relation to fiscal space, surgical system and

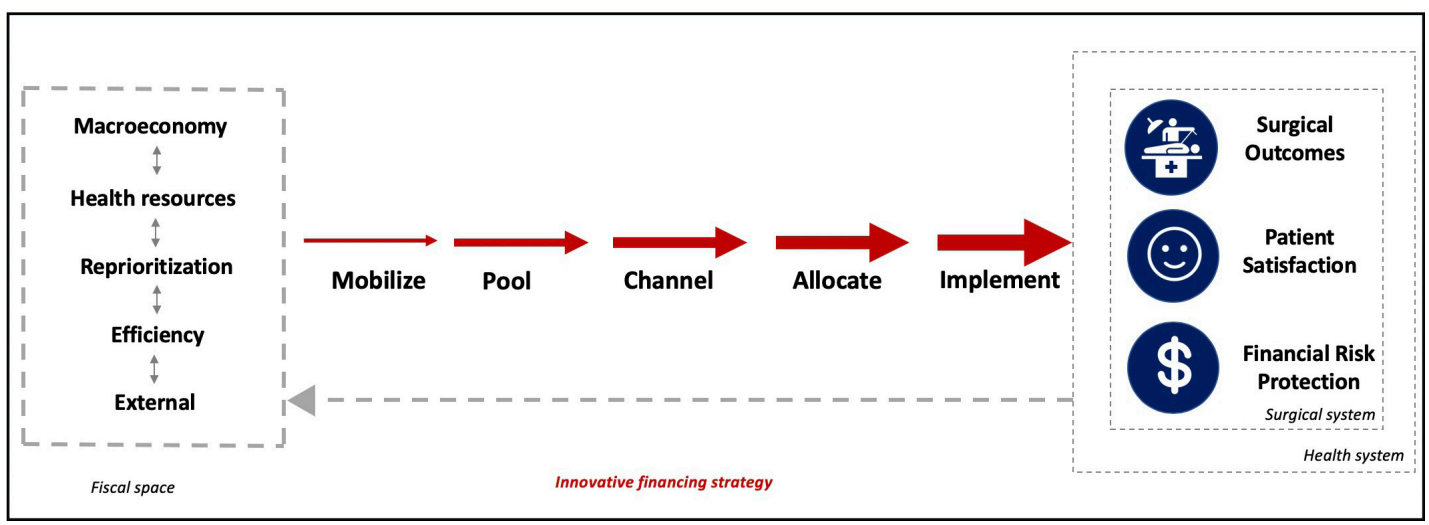

Figure 5 Framework for innovative financing and surgical systems. Source: original. 
the broader health system, determines the extent to which value increases. When designing new innovative financing mechanisms, the organising principle should be that of maximising value defined by the surgical system.

For the proposed framework to be useful, two areas must be addressed: (1) who will use the framework? and: (2) how will they use it? At a national level, governments could use the framework to design specific and contextually relevant, innovative financing strategies for NSOAP financing. This would entail a collaborative effort between relevant parts of government-ministries of health or finance, for example-working with academia or non-governmental organisations to design innovative strategies for the domestic setting. However, development banks (eg, African Development Bank), regional entities (eg, Southern African Development Community), philanthropic bodies, non-governmental organisations, and the private sector could apply this methodology to support individual countries, or country blocs, to fund scale-up of surgical care. This means carefully constructing all aspects of the value chain and creating inclusive governance and accountability mechanisms to attain surgical system goals: health outcomes, financial risk protection and patient satisfaction.

The first step, resource mobilisation, can be approached with different tactics and stakeholders in mind, from microlevies introduced by governments to impact investing by the private sector entities. Bilateral and multilateral agencies, philanthropic foundations, non-governmental organisations and private companies could all play a role in this step. It is important that the contributions of all possible stakeholders are pooled for maximum impact, without restrictive individual stipulations on the use of the mobilised funds. The mobilised funds could be channelled at an amount appropriate for the breadth and scope of the planned scale-up: at global, regional, national and subnational levels. Allocation of the available funds could be targeted at specific priority areas, for example, UHC packages aimed at addressing the essential surgery components laid out by the Disease Control Priorities third Edition, ${ }^{57}$ supporting current country commitments by funding achievement of regional targets, such as the Cape Town Declaration on Rheumatic Heart Disease ${ }^{58}$ or advancing the NSOAP pillars. It is essential that funding is allocated to specific interventions that consist of a core set of measurable and feasible (factoring in the specificity of the context) activities at a given cost. This will help calculate the contours of Return on Investment, required to attract additional funding and promote confidence in implementing bodies that surgery is a worthy investment with positive, measurable health and economic outcomes, over a finite period, and at a specific cost. Such funding may be performance enhancing, for instance, to implement NSOAPs based on specific criteria (eg, consistent leadership, alignment of professional societies and involvement of civil society), technical assistance provided by a local non-governmental/civil society organisation or for providing incentives that encourage collaboration and accountability between implementers.

\section{CONCLUSION}

Innovative financing is a novel approach for providing new and additional funding for global health. This paper highlights some examples of innovative financing that have attained scale in global health. NSOAPs are cost-effective complex health system innovations that require sustained funding over many years. Changing trends in DAH, coupled with constrained national budgets, means a systematic approach to increasing and sustaining health system financing is necessary. Innovative financing could help expand available funds for NSOAP implementation to scale up surgical care while strengthening health systems for better health outcomes.

\section{Author affiliations}

${ }^{1}$ Program in Global Surgery and Social Change, Department of Global Health and Social Medicine, Harvard Medical School, Boston, Massachusetts, USA

${ }^{2}$ Department of Plastic and Oral Surgery, Boston Children's Hospital, Boston, Massachusetts, USA

${ }^{3}$ Department of Surgery, NewYork-Presbyterian Hospita//Weill Cornell Medical Center, New York, New York, USA

${ }^{4}$ Center for Global Surgery Evaluation, Massachusetts Eye and Ear Infirmary, Boston, Massachusetts, USA

${ }^{5}$ Department of Global Health Equity, Department of Otology and Laryngology, Harvard Medical School, Boston, Massachusetts, USA

${ }^{6}$ Global Health and Population, Harvard University T H Chan School of Public Health, Boston, Massachusetts, USA

${ }^{7}$ Department of Global Health and Social Medicine, Harvard Medical School, Boston, Massachusetts, USA

Twitter Ché L Reddy @CheLenReddy, Alexander W Peters @alexpeters, Desmond Tanko Jumbam @desmondtanko, John G Meara @JohnMeara and Rifat Atun @RifatAtun

Contributors CLR conceived the study. CLR, AWP, LC, DTJ and RA developed the manuscript and original analysis. RA, JM and BCA provided critical analysis and revision to the entire manuscript. All authors read and approved the final manuscript.

Funding The Program in Global Surgery and Social Change receives funding from the GE Foundation as part of the SS2020 program and Blake Alkire has received funding from Mercy Ships, both unrelated to this manuscript.

Competing interests None declared.

Patient consent for publication Not required.

Provenance and peer review Not commissioned; externally peer reviewed.

\section{Data availability statement № additional data are available}

Open access This is an open access article distributed in accordance with the Creative Commons Attribution Non Commercial (CC BY-NC 4.0) license, which permits others to distribute, remix, adapt, build upon this work non-commercially, and license their derivative works on different terms, provided the original work is properly cited, appropriate credit is given, any changes made indicated, and the use is non-commercial. See: http://creativecommons.org/licenses/by-nc/4.0/.

\section{ORCID iDs}

Ché L Reddy http://orcid.org/0000-0002-8800-7359

Desmond Tanko Jumbam http://orcid.org/0000-0002-3062-2519

Rifat Atun http://orcid.org/0000-0002-1531-5983 


\section{REFERENCES}

1 Universal health coverage political Declaration, 2019. Available: https://www.un.org/pga/73/wp-content/uploads/sites/53/2019/05/ UHC-Political-Declaration-zero-draft.pdf

2 68th World Health Assembly. WHA 68.15 strengthening emergency and essential surgical care and anaesthesia as a component of universal health coverage. Provisional Agenda Item 2015;51:16-18.

3 Bishop D, Dyer RA, Maswime S, et al. Maternal and neonatal outcomes after caesarean delivery in the African surgical outcomes study: a 7-day prospective observational cohort study. Lancet Glob Health 2019;7:e513-22.

4 Alliance for Maternal and Newborn Health Improvement (AMANHI) mortality study group. Population-Based rates, timing, and causes of maternal deaths, stillbirths, and neonatal deaths in South Asia and sub-Saharan Africa: a multi-country prospective cohort study. Lancet Glob Health 2018;6:e1297-308.

5 Biccard BM, Madiba TE, Kluyts H-L, et al. Perioperative patient outcomes in the African surgical outcomes study: a 7-day prospective observational cohort study. Lancet 2018;391:1589-98.

6 Kruk ME, Gage AD, Arsenault C, et al. High-Quality health systems in the sustainable development goals era: time for a revolution. Lancet Glob Health 2018;6:e1196-252.

7 Rayne S, Burger S, Straten SV, et al. Setting the research and implementation agenda for equitable access to surgical care in South Africa. BMJ Glob Health 2017;2:e000170.

8 Dell AJ, Kahn D. Where are general surgeons located in South Africa? S Afr J Surg 2018;56:12-20.

9 Holmer H, Lantz A, Kunjumen T, et al. Global distribution of surgeons, anaesthesiologists, and obstetricians. Lancet Glob Health 2015;3 Suppl 2:S9-11.

10 Dell AJ, Kahn D. Surgical resources in South Africa: a review of the number of functional operating theatres. S Afr J Surg 2018;56:2-8.

11 Nyberger K, Jumbam DT, Dahm J, et al. The situation of safe surgery and anaesthesia in Tanzania: a systematic review. World J Surg 2019;43:24-35.

12 Burssa D, Teshome A, Iverson K, et al. Safe surgery for all: early lessons from implementing a national Government-Driven surgical plan in Ethiopia. World J Surg 2017;41:3038-45.

13 Kickbusch I, Gleicher D. Governance for health in the 21st century. WHO, 2012: 1-106.

14 Frenk J, Moon S. Governance challenges in global health. N Engl J Med 2013;368:936-42.

15 Jumbam DT, Reddy CL, Roa L, et al. How much does it cost to scale up surgical systems in low-income and middle-income countries? BMJ Glob Health 2019;4:e001779.

16 Dieleman J, Campbell M, Chapin A, et al. Evolution and patterns of global health financing 1995-2014: development assistance for health, and government, prepaid private, and out-of-pocket health spending in 184 countries. The Lancet 2017;389:1981-2004.

17 Moon S, Omole O. Development assistance for health: critiques, proposals and prospects for change. Health Econ Policy Law 2017;12:207-21.

18 Institute for health metrics and evaluation. Available: http://www. healthdata.org/institute-health-metrics-and-evaluation [Accessed 20 Feb 2019].

19 Atun R, Silva S, Knaul FM. Innovative financing instruments for global health 2002-15: a systematic analysis. Lancet Glob Health 2017;5:e720-6.

20 Hecht R, Palriwala A, Rao A. Innovative financing for global health: a moment for expanded us engagement? Cent Strateg Int Stud, 2010.

21 Douste-Blazy P. Innovative financing for development. Rep LIFE Lead Innov Financ Equity, 2009.

22 Citron I, Jumbam D, Dahm J, et al. Towards equitable surgical systems: development and outcomes of a national surgical, obstetric and anaesthesia plan in Tanzania. BMJ Glob Health 2019;4:e001282.

23 Albutt K, Sonderman K, Citron I, et al. Healthcare leaders develop strategies for expanding national surgical, obstetric, and anaesthesia plans in who AFRO and EMRO regions. World $J$ Surg 2019;43:360-7.

24 The Bulletin. Implementing World health assembly resolution 68.15: national surgical, obstetric, and anesthesia strategic plan development-the Zambian experience, 2017. Available: http:// bulletin.facs.org/2017/06/implementing-world-health-assemblyresolution-68-15/ [Accessed 19 Feb 2019].

25 Siddiqui S, Vervoort D, Peters AW, et al. Closing the gap of children's surgery in Pakistan. World Jnl Ped Surgery 2019;2:e000027.

26 Meara JG, Leather AJM, Hagander L, et al. Global surgery 2030: evidence and solutions for achieving health, welfare, and economic development. The Lancet 2015;386:569-624.

27 Roa L, Jumbam DT, Makasa E, et al. Global surgery and the sustainable development goals. Br J Surg 2019;106:e44-52.
28 Atun R, de Jongh T, Secci F, et al. Integration of targeted health interventions into health systems: a conceptual framework for analysis. Health Policy Plan 2010;25:104-11.

29 Kyratsis Y, Atun R, Phillips N, et al. Health systems in transition: professional identity work in the context of shifting institutional logics. Acad Manage J 2017;60:610-41.

30 Atun RA, Menabde N, Saluvere K, et al. Introducing a complex health innovation-Primary health care reforms in Estonia (multimethods evaluation). Health Policy 2006;79:79-91.

31 PGSSC. 2019 Dubai national surgical, obstetrics and anesthesia planning conference for who regional officers, high-level authorities, and Funders. Available: https://www.pgssc.org/2019-nationalsurgical-planning [Accessed 4 Apr 2019].

32 Rwanda national, obstetric and anaesthesia plan: 2018-2024. Available: https://docs.wixstatic.com/ugd/d9a674_c5c36059456a 416480fd58fd553ef302.pdf

33 Tanzania national surgical, obstetric and anaesthetic plan: 20182025, 2018. Available: https://docs.wixstatic.com/ugd/d9a674_4daa 353b73064f70ab6a53a96bb84ace.pdf

34 Nigeria national, obstetric and anaesthesia plan: 2019-2023. Available: https://docs.wixstatic.com/ugd/d9a674_1f7aa8161c95 4e2dbf23751213bc6f52.pdf

35 Surgical ZN. Zambian national surgical, obstetric, and anaesthesia strategic plan (NSOASP) year 2017-2021. Available: https://docs. wixstatic.com/ugd/d9a674_70f6813fe4e74c4d99eb028336a38745. pdf

36 SADC secretariat. Media Statement - Joint Meeting of SADC Ministers of Health 2018, 2018. Available: https://www.sadc.int/ files/3315/4169/8409/Media_Statement_-_Joint_Meeting_of_SADC_ Ministers_of_Health_and_those_responsible_for_HIV_and_AIDS_. pdf

37 World bank open data. Available: https://data.worldbank.org/ [Accessed 20 Feb 2019].

38 Dieleman JL, Campbell M, Chapin A, et al. Future and potential spending on health 2015-40: development assistance for health, and government, prepaid private, and out-of-pocket health spending in 184 countries. The Lancet 2017;389:2005-30.

39 Addis Ababa action agenda of the third International Conference on financing for development, 2015. Available: https://www.un.org/esa/ ffd/wp-content/uploads/2015/08/AAAA_Outcome.pdf

40 External health expenditure (\% of current health expenditure). Available: https://data.worldbank.org/indicator/SH.XPD.EHEX.CH.ZS [Accessed 18 May 2019].

41 UNICEF. Health budget South Africa 2018/2018. Available: https:// www.unicef.org/esaro/UNICEF_South_Africa_-_2017_-_Health Budget_Brief.pdf [Accessed 17 Sep 2019].

42 Abuja Declaration, 2001. Available: https://www.who.int/ healthsystems/publications/abuja_report_aug_2011.pdf?ua=1

43 Breakdown of 2019 FGN Budget Proposal - Budget Office of the Federation - Federal Republic of Nigeria. Available: https://www. budgetoffice.gov.ng/index.php/breakdown-of-2019-fgn-budgetproposal [Accessed 3 Oct 2019].

44 Atun R, Chang AY, Ogbuoji O, et al. Long-Term financing needs for HIV control in sub-Saharan Africa in 2015-2050: a modelling study. BMJ Open 2016;6:e009656-9.

45 Innovative Financing for Development: Scalable Business models that produce economic, Social, and environmental outcomes. Innovative financing initiative an initiative of the global development incubator, 2014.

46 The World Bank. Innovative finance for development solutions: initiatives of the world bank group. Washington DC, USA: World Bank Group, 2009. http://siteresources.worldbank.org/CFPEXT/ Resources/IF-for-Development-Solutions.pdf

47 Atun R, Knaul FM, Akachi Y, et al. Innovative financing for health: what is truly innovative? Lancet 2012;380:2044-9.

48 Gargasson JL, Salomé B. The role of innovative financing mechanisms for health, 2010.

49 Atun R. Health systems, systems thinking and innovation. Health Policy Plan 2012;27 Suppl 4:iv4-8.

50 Atun R. Innovative financing (B): UNITLIFE Rifat Atun and Gabriel Seidman 1, 2015: 1-19.

51 Heller PS. Understanding fiscal space. This Policy Discuss Pap, 2005: 19.

52 Tandon A, Cashin C. Assessing public expenditure on health from a fiscal space perspective. Washington, DC: World Bank, 2010. http://documents.worldbank.org/curated/en/333671468330890417/ Assessing-public-expenditure-on-health-from-a-fiscal-spaceperspective

53 Lane C. Rwanda: fiscal space for health and the MDGs revisited, 2009. 
54 Dijkstra A, Beckerman P, Dimitrova D, et al. Fiscal space profiles of countries in eastern and southern Africa: case study - Kenya fiscal space analysis, 2017.

55 Jamison DT, Summers LH, Alleyne G, et al. Global health 2035: a world converging within a generation. Lancet 2013;382:1898-955.

56 Verguet S, Gauvreau CL, Mishra S, et al. The consequences of tobacco tax on household health and finances in rich and poor smokers in China: an extended cost-effectiveness analysis. Lance Glob Health 2015;3:e206-16.

57 Gawande A, Debas HT, Donkor P, et al. Disease control priorities. 3rd Edn. Washington DC: World Bank Group, 2015.

58 Zilla P, Bolman RM, Yacoub $\mathrm{MH}$, et al. The Cape town Declaration on access to cardiac surgery in the developing world. Cardiovasc J Afr 2018;29:256-9.

59 Citron I, Sonderman K, Subi L, et al. Making a case for national surgery, obstetric, and anesthesia plans. Can J Anaesth 2019;66:263-71.

60 Financing Global Health. Institute for Health Metrics and Evaluation (IHME)Visualization Hub. Available: http://vizhub.healthdata.org/fgh [Accessed 4 Oct 2019].

61 The global fund: 2018 annual financial report, 2018. Available: https://www.theglobalfund.org/media/8470/corporate_ 2018annualfinancial report en.pdf

62 Warren AE, Wyss K, Shakarishvili G, et al. Global health Initiative investments and health systems strengthening: a content analysis of global fund investments. Global Health 2013;9:30.

63 The global fund: private and Nongovernment partners: (red). Available: https\%3a\%2f\%2fwww.theglobalfund.org\%2fen\%2fprivate-ngopartners\%2fresource-mobilization\%2fred\%2f [Accessed 26 Apr 2019].

64 The global fund Welcomes product red. Available: https $\% 3 a \% 2 f \%$ 2 fwww.theglobalfund.org\%2fen\%2fnews\%2f2006-01-26-the-globalfund-welcomes-product-red\%2f [Accessed 26 Apr 2019].

65 The Vaccine Alliance AS. 2017 Pneumococcal AMC Annual Report: 1 January - 31 December 2017. Available: https://www.gavi.org/ library/gavi-documents/amc/2017-pneumococcal-amc-annualreport/

66 About Gavi, the vaccine alliance. Available: https://www.gavi.org/ about/ [Accessed 26 Apr 2019].

67 Overview - International Finance Facility for Immunisation. Available: https://www.iffim.org/about/overview/ [Accessed 23 Aug 2019].

68 Children's Investment Fund Foundation, About Us, Endowment. Available: https://ciff.org/about-us/endowment/ [Accessed $26 \mathrm{Apr}$ 2019]

69 Larry Fink's Letter to CEOs. BlackRock. Available: https://www. blackrock.com/corporate/investor-relations/larry-fink-ceo-letter [Accessed 22 Jun 2019].

70 Children's Investment Fund Foundation Annual Report: 2017, 2019. Available: https://ciff.org/documents/828/CIFF_AnnualReport_2017. pdf

71 Atun R, Aydın S, Chakraborty S, et al. Universal health coverage in turkey: enhancement of equity. Lancet 2013;382:65-99.

72 Organisation mondiale de la santé. Who report on the global tobacco epidemic, 2015: raising taxes on tobacco, 2015.

73 Sornpaisarn B. Resource tool on alcohol taxation and pricing policies, 2017.

74 Taxes on sugary drinks: why do it? 2017. Available: https://apps. who.int/iris/bitstream/handle/10665/260253/WHO-NMH-PND-16. 5Rev.1-eng.pdf?sequence=1 [Accessed 17 Nov 2019].

75 Barroy H, Sparkes S, Dale E. Assessing fiscal space for health in low and middle income countries: a review of the evidence, 2016.

76 Binagwaho A, Kyamanywa P, Farmer PE, et al. The human resources for health program in Rwanda--new partnership. N Engl J Med 2013;369:2054-9.

77 South Africa - Results - The Global Fund Data Explorer. Available: https://data.theglobalfund.org/investments/results/ZAF [Accessed 17 Nov 2019]. 